\title{
The immunoglobulin D Fc receptor expressed on fibroblast-like synoviocytes from patients with rheumatoid arthritis contributes to the cell activation
}

\author{
Yu-jing WU\#, Wen-sheng CHEN*, Heng-shi CHEN, Xing DAI, Jin DONG, Ying WANG, Ling-ling ZHANG, Yan CHANG, Qiong \\ HUANG, Xiao-yi JIA, Wei WEI* \\ Institute of Clinical Pharmacology, Anhui Medical University, Key Laboratory of Anti-inflammatory and Immune Medicine, Ministry of \\ Education, Anhui Collaborative Innovation Center of Anti-inflammatory and Immune Medicine, Hefei 230032, China
}

\begin{abstract}
Immunoglobulin IgD might play an important role in autoimmune diseases, but the function of lgD has remained elusive, despite multiple attempts to define its biological function. Fibroblast-like synoviocytes (FLSs) are specialized cells of the synovium that play a key role in the pathogenesis of rheumatoid arthritis (RA). In this study we explored the possible roles of excessive IgD expression on the function of FLSs from RA patients (RA-FLSs). We showed that IgD Fc receptor (IgDR) was constitutively expressed on FLSs, and was significantly elevated in RA-FLSs compared with FLSs prepared from synovial tissues of healthy controls (HC-FLSs). Furthermore, IgDR was mainly detected on the cell surface and in the cytoplasm. We further detected the intrinsic binding affinity of IgD to IgDR on HC-FLSs with an equilibrium dissociation constant $\left(K_{\mathrm{D}}\right)$ of $0.067 \mathrm{nmol} / \mathrm{L}$. Incubation of RA-FLSs with $\mathrm{lgD}(1-10 \mu \mathrm{g} / \mathrm{mL})$ for $48 \mathrm{~h}$ dosedependently promoted the expression of IgDR, and stimulated the production of inflammatory cytokines and chemokines, such as IL-1 $\beta$, IL-6, monocyte chemotactic protein (MCP)-1, TNF- $\alpha$ and receptor activator of nuclear factor-kB ligand (RANKL), thus potentially contributing to IgD-IgDR crosslinking. Moreover, incubation with IgD $(0.1-10 \mu \mathrm{g} / \mathrm{mL})$ for $48 \mathrm{~h}$ dose-dependently enhanced viability for both HC-FLSs and RA-FLSs. Our results demonstrate that IgDR is expressed on RA-FLSs and contributes to the activation of FLSs, and suggest that IgD-IgDR is a potential novel immunotherapeutic target for the management of RA.
\end{abstract}

Keywords: rheumatoid arthritis; immunoglobulin D; immunoglobulin D Fc receptor; fibroblast-like synoviocytes; fluorescence based receptor binding assay; inflammatory cytokines

Acta Pharmacologica Sinica (2017) 38: 1466-1474; doi: 10.1038/aps.2017.105; published online 3 Aug 2017

\section{Introduction}

The immunoglobulin $\operatorname{IgD}$ can be expressed as membrane $\operatorname{IgD}(\mathrm{mIgD})$ representing one of two B cell receptors with an attached signaling machinery or can be secreted as an antibody $(\mathrm{sIgD})^{[1]}$. IgD has been found to be increased in several diseases, such as IgD myeloma, tuberculosis, chronic obstructive pulmonary diseases, Hodgkin's disease, hyper IgE and hyper IgD syndromes ${ }^{[2]}$. Furthermore, sIgD levels are increased in autoimmune disorders such as rheumatoid arthritis (RA) and systemic lupus erythematosus $(\mathrm{SLE})^{[1-4]}$. However, high expression of sIgD is associated with increased protein-like sediments and cell necrosis in the kidney, spleen and liver in transgenic mice ${ }^{[5]}$. Recent studies have suggested that IgD

\footnotetext{
\# These authors contributed equally to this work.

* To whom correspondence should be addressed.

E-mail wwei@ahmu.edu.cn

Received 2016-12-30 Accepted 2017-04-04
}

might play an important role in autoimmune diseases, and the function of $\operatorname{IgD}$ has remained elusive since its discovery, despite multiple attempts to define its biological function.

Many lymphoid and non-lymphoid cells express surface membrane receptors, and many studies have focused on specific structures located in the constant region of immunoglobulin molecules $(\mathrm{FcR})^{[6]}$, such as immunoglobulin A (IgA), IgE, IgG, and IgM. Surprisingly, an Fc receptor specific for IgD (FcסR or IgDR) has been suggested to exist on $\mathrm{T}$ cells ${ }^{[7]}$; however, early attempts to detect its expression have produced variable and conflicting results ${ }^{[8]}$. Through quantitative immunofluorescence techniques, binding of IgD to T cells and basophilic cell lines has been demonstrated, and an increase in $\delta^{+}$T cells in vivo has also been observed, thus suggesting that a putative IgDR on T cells may play a role regulating $\operatorname{IgD}^{[2,4,9]}$. Recently, our group has reported further evidence of the existence of an IgDR, demonstrating that human IgD antibody induces cell proliferation in the human Burkitt lymphoma B cell line, Daudi, potentially 
by activating the putative IgDR and consequently initiating a tyrosine phosphorylation signaling cascade that accelerates the $G_{1} / S$ transition ${ }^{[10]}$. Furthermore, we have reported that in RA patients, the levels of $\operatorname{sgD}, \mathrm{mIgD}$ and $\operatorname{IgDR}$ are higher than those in healthy controls, and after treatment with $\operatorname{IgD}$ antibodies, the expression of IgDR on peripheral T and B cells significantly increases, thereby possibly contributing to RA pathogenesis ${ }^{[11]}$.

RA is a chronic inflammatory autoimmune disease characterized by synovial hyperplasia and chronic inflammation. A marked increase in macrophage-like and fibroblast-like synoviocytes (FLSs) in the synovial membrane and the accompanying inflammatory infiltration of other immune cells such as synovial macrophages result in bone erosion and joints destruction. Accumulating evidence indicates that activated FLSs in RA patients contribute to joint destruction, and the possible roles of excessive $\operatorname{IgD}$ expression on the function of FLSs from RA patients (RA-FLSs) are discussed in this work. The expression of IgDR has been described on $\mathrm{CD} 4^{+}$and $\mathrm{CD} 8^{+}$ $\mathrm{T}$ cells in mice and humans ${ }^{[1,3,11]}$. However, the role of IgDR on cells of the synovial infiltrate has not yet been studied. Therefore, we investigated the expression of IgDR in RA-FLSs and explored the effects of IgD. We identified IgD-binding IgDR as a $\sim 70 \mathrm{kDa}$ protein complex that was detected on FLSs by using flow cytometry and confocal laser scanning microscopy. Studies of the binding properties indicated that human $\operatorname{IgD}$ bound to $\operatorname{IgDR}$ with an equilibrium dissociation constant $\left(K_{\mathrm{D}}\right)$ of $0.067 \mathrm{nmol} / \mathrm{L}$. Furthermore, we found that IgD significantly promoted the viability of FLSs, induced cytokines/ chemokine secretion and increased the expression of IgDR in FLSs, thus potentially contributing to RA pathogenesis.

\section{Materials and methods Reagents}

Human IgD was purchased from Abcam (Cambridge, MA, USA). Biotinylated $\operatorname{IgD}$ was prepared in our laboratory with a protein biotinylation kit from Pierce Biotechnology (Rockford, IL, USA), according to the manufacturer's instructions ${ }^{[12]}$. APC-Cy7 conjugated streptavidin, PE conjugated anti-IgD antibody and IgG1 isotype control were purchased from BD Pharmingen (San Diego, CA, USA).

\section{Preparation and culture of FLSs}

Human synovial membranes were obtained from patients with RA undergoing arthroscopy. The diagnosis of RA conformed to the American College of Rheumatology revised criteria from $1987^{[13]}$. Normal knee tissues were obtained from donors undergoing traumatic surgery. Synovial tissues were minced and digested with type IA collagenase for $3 \mathrm{~h}$, filtered, extensively washed and then cultured in DMEM containing $20 \%$ fetal bovine serum (FBS, Sigma-aldich, MO, USA) at $37^{\circ} \mathrm{C}$ in a humidified atmosphere of $5 \% \mathrm{CO}_{2}$. At confluence, adherent cells were trypsinized, split in a 1:3 ratio, and recultured in medium ${ }^{[14]}$. The spindle-shaped cells at passage 3 were used in subsequent experiments, during which time they were a homogeneous population of FLSs. The study protocol was carried out in accordance with the Declaration of Helsinki (2008) and was approved by the Ethics Committee of Anhui Medical University. Written informed consent was obtained from each participant before the start of the study.

\section{Flow cytometry analysis}

Expression of IgDR was detected by treatment of FLSs with biotinylated IgD. For detecting IgD binding receptors, a total of $1 \times 10^{6}$ cells were washed twice with PBS and incubated with $1 \mu \mathrm{g}$ of biotinylated $\mathrm{IgD}$ for $30 \mathrm{~min}$ at room temperature (RT). After washing, APC-Cy7 conjugated streptavidin was added, and cells were incubated for an additional $30 \mathrm{~min}$ on ice and washed again. Cells stained with APC-Cy7 conjugated streptavidin alone were used as an isotype control. For assessment of $\mathrm{IgD}$, a total of $1 \times 10^{6}$ cells were washed twice with PBS and incubated with PE conjugated anti-IgD antibodies for $30 \mathrm{~min}$ at RT, and the IgG1 isotype control was also matched. To determine the ability of $\operatorname{IgD}$ to induce the expression of $\operatorname{IgDR}$, FLS were stimulated with IgD for $48 \mathrm{~h}$ or were left unstimulated. After incubation, expression of IgDR was detected with biotinylated IgD followed by APC-Cy7 conjugated streptavidin. Data were acquired on a FC 500 flow cytometer (Beckman Coulter Ltd, CA, USA ) and analyzed with CXP analysis software (Beckman Coulter Ltd, CA, USA).

\section{Confocal microscopy analysis}

FLSs were plated on coverslips and fixed with $4 \%$ paraformaldehyde for $20 \mathrm{~min}$ at RT. Then, cells were permeabilized with $0.2 \%$ Triton X-100 for $10 \mathrm{~min}$ at RT and washed with PBS three times. After being blocked with 1\% BSA in PBS for $1 \mathrm{~h}$ at RT, biotinylated $\operatorname{IgD}$ was added, and cells were incubated overnight at $4^{\circ} \mathrm{C}$. After being washed with PBS three times, cells were stained with streptavidin labeled APC-Cy7 secondary antibody for $2 \mathrm{~h}$ at $37^{\circ} \mathrm{C}$. Cells were then washed with PBS buffer three times. When the coverslips were dry, a mounting solution containing DAPI (Vector Laboratories, Inc, Burlingame, CA, USA) was applied, and images were taken using a SP8 confocal laser scanning microscope (Leica, Wetzlar, Germany). The expression of IgDR was quantitatively analyzed using ImageJ software.

Fluorescence based receptor binding assay and Scatchard analysis Protocols were used to evaluate the intrinstic binding affinity of fluorescence labeled $\operatorname{IgD}$ antibody to $\operatorname{IgD}$ on $\operatorname{IgDR}$ in FLSs. Binding of IgD for detection by flow cytometry was done as described below. Various concentrations of $\operatorname{IgD}(0.003,0.01$, $0.03,0.1,0.3,1,3,10 \mu \mathrm{g} / \mathrm{mL}$ ) were used. Maximal binding of IgD was observed on FLS in 6-well microtiter plates at $1 \times 10^{6}$ cells/well, incubated at $37^{\circ} \mathrm{C}$ for $2 \mathrm{~h}$ in fresh medium (with $0.1 \% \mathrm{BSA}$ ), then cells were washed three times with PBS at RT, then with buffer appropriate to the assay. Binding of $\operatorname{IgD}$ was detected with PE conjugated anti-IgD antibody, and IgG1 isotype control was used to calculate non-specific binding. The binding of $\operatorname{IgD}$ to the anti-IgD antibody was analyzed by using flow cytometry. To measure the affinity of the fluorescent ligand $\operatorname{IgD}$, the intensity values corresponding to the maximum 
of fluorescence emission were plotted against the total ligand concentrations. The ligand binding properties were evaluated by using the fluorescence intensities, assuming that the protein was $100 \%$ active, with a stoichiometry of $1: 1$ (protein:ligand) at saturation. The curves were made linear by using Scatchard Plots. The $K_{\mathrm{D}}$ values for IgD protein were calculated ${ }^{[15,16]}$.

\section{Western blot}

FLSs were added to 6-well microtiter plates at $1 \times 10^{6}$ cells/well, stimulated with $\operatorname{IgD}(1,3,10 \mu \mathrm{g} / \mathrm{mL})$ for $48 \mathrm{~h}$ and incubated at $37^{\circ} \mathrm{C}$ with $5 \% \mathrm{CO}_{2}$. After culture, FLSs were lysed and centrifuged at $2000 \times \mathrm{g}$ for $20 \mathrm{~min}$ at $4^{\circ} \mathrm{C}$. The supernatants of cultures were recollected and kept frozen at $-80^{\circ} \mathrm{C}$ until use. Protein samples were fractionated through $10 \%$ SDS-polyacrylamide gel electrophoresis and transferred onto polyvinylidene fluoride (PVDF) microporous membranes (Bio-Rad, Shanghai, China). After membranes were blocked with blocking buffer $(0.05 \%$ Tween 20-PBS with $5 \%$ non-fat milk) at $37^{\circ} \mathrm{C}$ for $2 \mathrm{~h}$, biotinylated IgD was used as a primary antibody to IgDR and incubated overnight at $4{ }^{\circ} \mathrm{C}$. Subsequently, cells were treated with HRP-conjugated streptavidin as a secondary antibody (Beyotime Institute of Biotechnology, Beijing, China) at $37^{\circ} \mathrm{C}$ for $2 \mathrm{~h}$. Immunodetection was performed using enhanced chemiluminescence reagent, according to the manufacturer's instructions. Equivalent protein loading and transfer efficiency were verified by staining for $\beta$-actin. GSM-3.0 gel graph analyzing system was used to calculate the numerical value of every blot.

\section{FLSs viability assay}

FLSs of human obtained, as described above, were added to 96-well microtiter plates at $2 \times 10^{4}$ cells/well in DMEM with $10 \%$ FBS. FLSs were stimulated with $\operatorname{IgD}(0.1,0.3,1,3,10$ $\mu \mathrm{g} / \mathrm{mL}$ ) for 24,48 , or $72 \mathrm{~h}$ in 96 -well plates (each group in triplicate wells) and incubated at $37^{\circ} \mathrm{C}$ under $5 \% \mathrm{CO}_{2}$. For each experiment, control cells were treated with medium only. A Cell Counting Kit-8 (WST-8; Dojindo Laboratories, Kumamoto, Japan) was used to explore the effects of IgD on FLS viability. Moreover, $10 \mu \mathrm{L}$ of WST-8 solution was added per well after co-culture. Blank controls included $100 \mu \mathrm{L}$ of DMEM and $10 \mu \mathrm{L}$ of WST-8 solution in triplicate wells ${ }^{[17]}$. The cells were incubated for $4 \mathrm{~h}$ at $37^{\circ} \mathrm{C}, 5 \% \mathrm{CO}_{2}$, and the absorbance at 450 $\mathrm{nm}$ was measured colorimetrically on an Elx-808 microplate reader (BioTek, VT, USA), according to the manufacturer's protocol. Proliferative responses were expressed as a stimulation index (SI), wherein the SI was equal to the absorbance at $450 \mathrm{~nm}$ in cells cultured with IgD divided by the absorbance in cells cultured with medium alone.

\section{Cytokine and chemokine assays}

FLSs were stimulated with $\operatorname{IgD}(0.1,0.3,1,3,10 \mu \mathrm{g} / \mathrm{mL})$ for $48 \mathrm{~h}$ in 24 -well plates and incubated at $37^{\circ} \mathrm{C}$ under $5 \% \mathrm{CO}_{2}$. The levels of inflammatory cytokines and chemokines, including (IL-1 $\alpha$, IL-1 $\beta$, TNF- $\alpha$, IL-6, IL-10, IL-8, IL-4, INF- $\gamma$, IL-13, and monocyte chemotactic protein (MCP)-1, in FLS supernatants were measured by using a quanti body human inflammation array 1 (RayBiotech, Norcross, USA). In addition, simultaneous quantification of the cytokines was performed on a GenePix 4000B microarray scanner (Molecular Devices, CA, USA). Human receptor activator of nuclear factor- $\mathrm{k} B$ ligand (RANKL) in supernatant samples was determined using the ELISA method (CUSABIO, Wuhan, China), according to the manufacturer's instructions.

\section{Statistical analysis}

Statistical analysis was performed with analysis of variance (ANOVA) in SPSS 11.5 software (SPSS, Inc, Chicago, IL, USA). ANOVA was used exclusively for multigroup comparisons. Parametric or nonparametric tests were used according to the normality of the distribution. Data are presented as the mean \pm standard error of the mean (SEM) unless otherwise indicated. Differences with $P$ values less than 0.05 were considered statistically significant.

\section{Results}

\section{IgDR is constitutively expressed on FLSs}

Flow cytometry was performed to identify the expression of $\mathrm{IgD}$ and IgDR on FLSs. As shown in Figure $1 \mathrm{~A}, 8.7 \%$ of RA-FLSs and $3.4 \%$ of HC-FLSs were positively stained with biotinylated IgDR. The expression of IgDR was indicated by histograms. Additionally, mIgD was undetectable on the surface of FLSs (Figure 1B). We further characterized the subcellular localization of IgDR in RA-FLSs and healthy controls (HC-FLSs) by confocal immunofluorescence microscopy (Figure 1C). As expected, IgDR was primarily localized on the cell membrane and in the cytoplasm. The mean fluorescence intensity (MFI) of IgDR was higher on of RA-FLSs than on HC-FLSs $(0.0419 \pm 0.007$ vs $0.0117 \pm 0.001, P=0.005$, Figure 1D).

\section{Dose-dependent binding between IgD and IgDR}

To determine whether the observed binding of $\operatorname{IgD}$ to $\operatorname{IgDR}$ on FLSs showed characteristics of receptor-ligand interaction, we determined receptor saturation and affinity of binding. The affinity of human IgD was detected with PE conjugated anti-IgD antibody. Binding of IgD to IgDR expressed on HC-FLSs was also determined with IgD as ligands. Our findings indicated that binding between $\operatorname{IgD}$ and $\operatorname{IgDR}$ was concentration-dependent (Figure 2A).

\section{Binding affinity}

We estimated the IgD binding affinity by using a fluorescence based receptor binding assay. The specific binding os IgD concentration was determined (Figure 2A). The Scatchard line transformed from the specific binding data was plotted (Figure $2 \mathrm{~B}) . B_{\max }$ and $K_{\mathrm{D}}$ values were calculated through Scatchard plot analysis as shown in Figure $2 \mathrm{~B}$. Moreover, the $K_{\mathrm{D}}$ value was $6.7 \times 10^{-11} \mathrm{~mol} / \mathrm{L}$, which corresponded to a high-affinity binding, whereas the $B_{\max }$ value was 6215 arbitrary units $/ 10^{4}$ cells (Figure 2B).

\section{IgD stimulated IgDR expression in RA-FLSs}

To examine whether IgD stimulated the expression of IgDR, flow cytometry and western blotting analysis were performed 
A

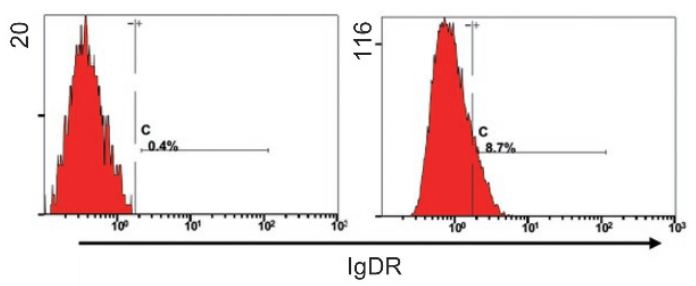

RA-FLSs Isotype MFI 0.497

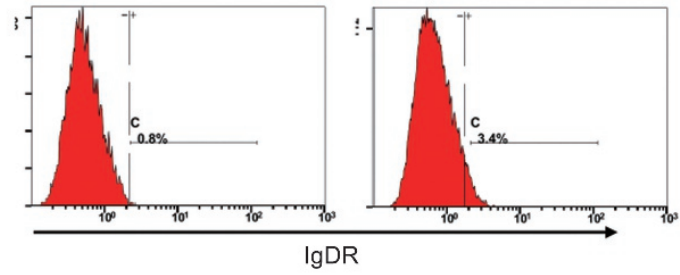

HC-FLSs Isotype MFI 0.54
IgDR MFI 0.93

B

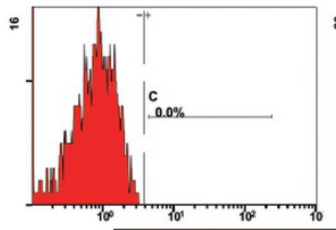

RA-FLSs Isotype MFI 0.566

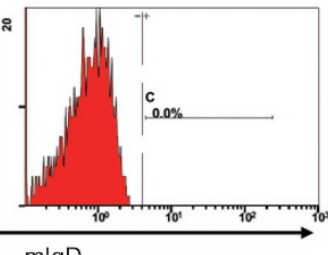

$\mathrm{mlg} \mathrm{D}$

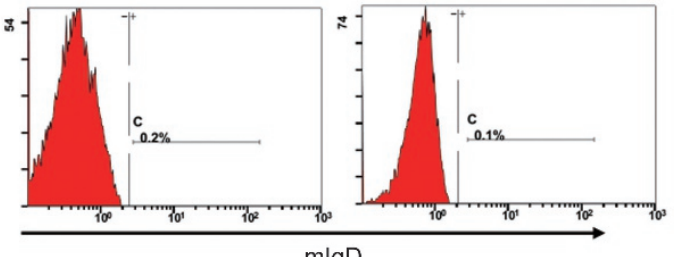

$\mathrm{mlgD}$

HC-FLSs Isotype MFI 0.638
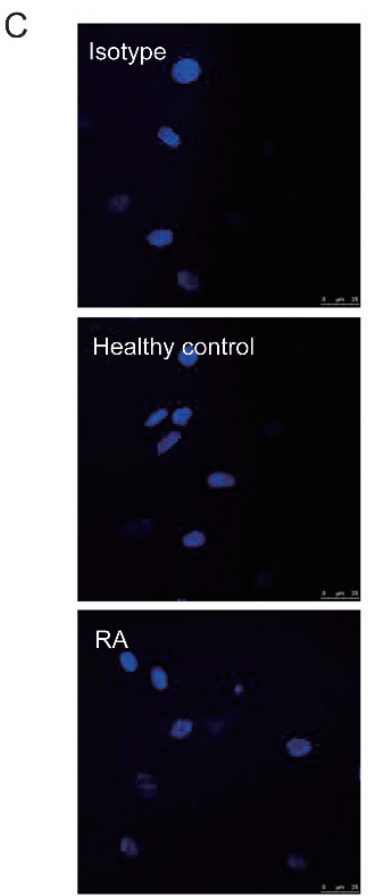

DAPI-nuclear
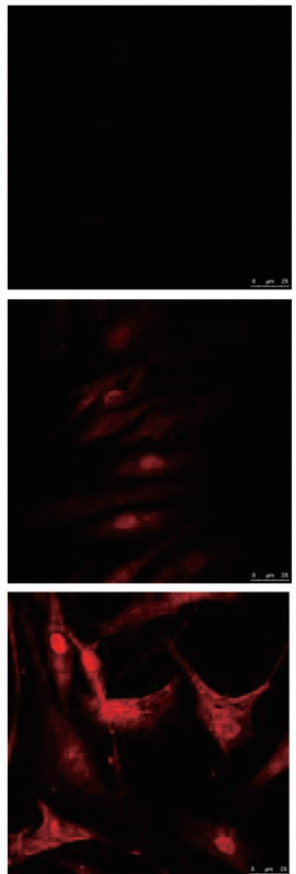

APC-cy7-IgDR
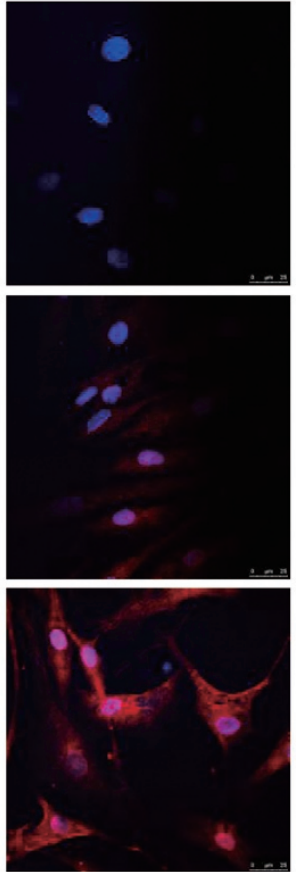

Merged image
D

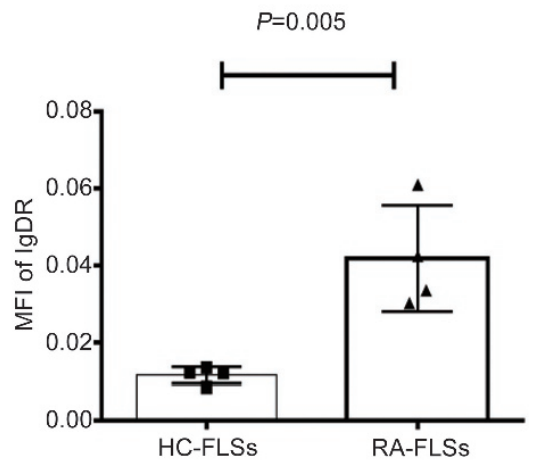

Figure 1. Expression of IgD and IgDR on FLSs. The expression of IgDR (A) and mIgD (B) was determined by flow cytometry and is indicated by the filled histograms. MFI: Mean fluorescence intensity. (C) Subcellular localization of IgDR in RA-FLSs and HC-FLSs, determined by confocal immunofluorescence microscopy. Colocalization was confirmed when the images were merged (right panel). Isotype matched control primary antibody staining is also shown in C (first line). (D) Quantification of IgDR expression by confocal microscopy analysis. Data represent the mean \pm SEM ( $n=4)$.

on RA-FLSs after they were co-cultured with $\operatorname{IgD}$ for $48 \mathrm{~h}$. As shown in Figure 3A, the MFI of IgDR on the surface of FLSs was upregulated in the presence of increasing $\operatorname{IgD}$ concentration (Figure 3B). Western blot analysis showed increased levels of IgDR in the $70 \mathrm{kDa}$ band after IgD stimulation (Figure $3 \mathrm{C}$ and $3 \mathrm{D})$, a result consistent with the flow cytometry results.

\section{IgD enhanced FLSs viability}

To determine the effect of excess IgD on the viability of the
FLSs, RA-FLSs and HC-FLSs were cultured under different concentrations of IgD for various times before viability was measured. As expected, the viability of FLSs was increased in response to treatment with $\operatorname{IgD}$. As shown in Figure 4 and Table 1, for RA-FLSs, IgD enhanced the viability of FLSs in a concentration-dependent manner after $48 \mathrm{~h}$ of treatment $(P<0.05)$, with an $\mathrm{EC}_{50}$ value of $4.243 \mu \mathrm{g} / \mathrm{mL}\left(R^{2}=0.897\right)$. After $72 \mathrm{~h}$, enhanced viability was still significant $(P<0.05)$, and the $\mathrm{EC}_{50}$ values were $3.316 \mu \mathrm{g} / \mathrm{mL}\left(R^{2}=0.836\right)$. These results sug- 
A

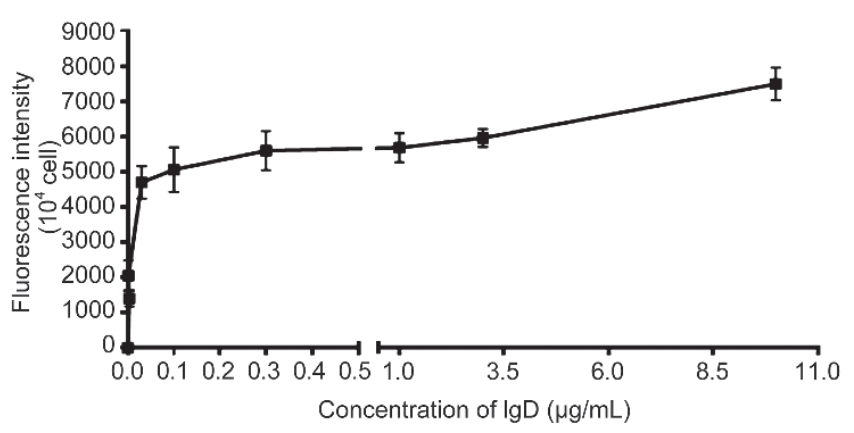

B

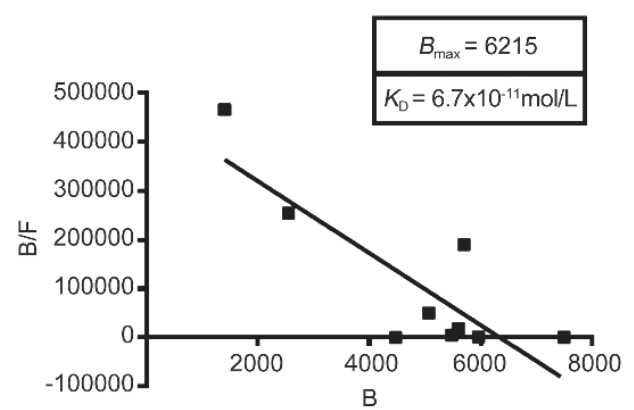

Figure 2. Ligand binding assays. HC-FLSs expressing IgDR were incubated with human IgD for $2 \mathrm{~h}$ at $37{ }^{\circ} \mathrm{C}$ and washed three times. The cells with bound fluorescent ligands were determined by flow cytometry. Values for nonspecific binding, determined by isotype control, were subtracted. Data are plotted as Scatchard analyses and are representative of several independent experiments, $n=4$. (A) The specific binding vs IgD concentrations was plotted. (B) The Scatchard line was transformed from the specific binding values. $B_{\max }$ and $K_{D}$ values were calculated by Scatchard plot analysis.

gested that the optimal stimulation time was $48 \mathrm{~h}$, and the optimal stimulation concentration ranged from 1 to $10 \mu \mathrm{g} / \mathrm{mL}$. In addition, we measured the effect of IgD stimulation on RAFLSs and HC-FLSs and found that IgD slightly enhanced RAFLS viability after $24 \mathrm{~h}$, whereas it had no significant effect on HC-FLSs. To a lesser extent, the viability of HC-FLSs was also increased after cultured with $\operatorname{IgD}$ for $48 \mathrm{~h}$. Together, these results demonstrated that RA-FLSs are more sensitive to $\operatorname{IgD}$ than HC-FLSs are.

IgD stimulated cytokine and chemokine secretion in RA-FLSs To further characterize the effects of IgD on RA-FLSs, we used a cytokine/chemokine antibody-based array to measure protein secretion by FLSs that were cultured in the presence or absence of $\mathrm{IgD}$. Compared with that in unstimulated cells, secretion of IL-1 $\beta$, IL-6, MCP-1 and TNF- $\alpha$ was significantly induced by IgD $(10 \mu \mathrm{g} / \mathrm{mL})(P<0.05)$, and secretion of RANKL was significantly induced by $\operatorname{IgD}(1 \mu \mathrm{g} / \mathrm{mL})(P<0.01)$ (Figure 5$)$.

\section{Discussion}

In RA, FLSs play an important role in responding to a proinflammatory environment, such as that associated with infiltration of lymphocytes and dendritic cells. In addition, FLSs in RA can act as an effector cell population that participates in synovial inflammation and joint destruction ${ }^{[18]}$.

The immunoglobulin IgD accounts for approximately $1 \%$ of the normal serum immunoglobulins and may be involved in different immunological mechanisms ${ }^{[1,4,19,20]}$. Receptors for the Fc portion of immunoglobulin molecules have been described on a number of lymphoid cells in mammals, including $\mathrm{T}$ cells, $\mathrm{B}$ cells and monocytes/macrophages ${ }^{[21,22]}$. Coico et al have identified IgDR-positive $\mathrm{T}$ cells by developing a rosetting assay ${ }^{[7]}$, and their results have indicated that $\operatorname{IgD}$ is a ligand for IgD-specific receptors. In contrast to IgG and IgE receptors, the structural and functional characteristics of the $\operatorname{IgD}$ receptor remain unknown because the gene encoding the IgD receptor has not yet been identified. Although accumulating evidence indicates that activated FLSs are key players in RA joint destruction, the roles of $\operatorname{IgD}$ and IgDR expression on FLSs have not been described. In this study, biotinylated $\operatorname{IgD}$ and flow cytometric analysis was used to detect the expression of IgDR on human FLSs ${ }^{[11]}$. We demonstrated that IgDR, not mIgD, was expressed on the surfaces of FLSs. Furthermore, we confirmed the subcellular localization of IgDR in FLS and showed that expression of IgDR was higher on RA-FLSs than on HC-FLSs.

To investigate whether IgD binding to FLSs had the characteristics of a receptor-ligand interaction, we established a fluorescence based receptor binding assay based on a radioactive ligand receptor binding assay and using a fluorescence labeled antibody ${ }^{[15,23,24]}$. We found that after shorter periods in culture, human FLSs bound IgD in a manner characteristic of receptor-ligand interactions. The binding affinity of $\operatorname{IgD}$ to IgDR on RA-FLSs was found to be high $\left(K_{D}=0.067 \mathrm{nmol} / \mathrm{L}\right)$ and similar to the $K_{\mathrm{D}}$ for binding to T cells (data not shown). In fact, the binding affinity of $\operatorname{IgD}$ was similar to the $K_{\mathrm{D}}$ for binding of canakinumab to IL- $1 \beta$ in RA patients $\left(K_{\mathrm{D}}=0.227\right.$ $\mathrm{nmol} / \mathrm{L})^{[25]}$ and was 800 times higher than that reported for

Table 1. Comparison of stimulating effect of IgD on FLSs between RA patients and healthy controls.

\begin{tabular}{|c|c|c|c|c|c|c|}
\hline Time (h) & \multicolumn{2}{|c|}{24} & \multicolumn{2}{|c|}{48} & \multicolumn{2}{|c|}{72} \\
\hline $\mathrm{EC}_{50}(\mu \mathrm{g} / \mathrm{mL})$ of $\lg \mathrm{D}$ & 66.3 & - & 4.243 & 6.674 & 3.316 & 5.242 \\
\hline 95\% Confidence intervals & $6.156-715.8$ & - & $3.287-5.476$ & $5.244-8.495$ & $2.211-4.975$ & $4.016-6.843$ \\
\hline$R^{2}$ & 0.519 & 0.096 & 0.897 & 0.880 & 0.836 & 0.899 \\
\hline
\end{tabular}


A
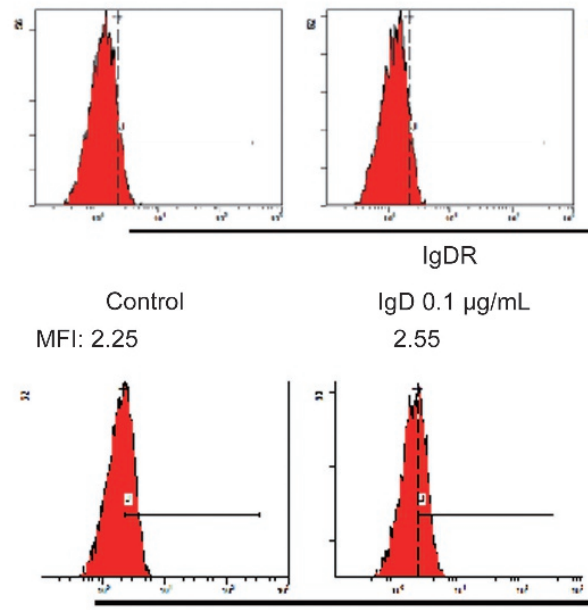

MFI: 3.94
$\operatorname{lgD} 1 \mu \mathrm{g} / \mathrm{mL}$
IgDR

$\operatorname{lgD} 0.1 \mu \mathrm{g} / \mathrm{mL}$ 2.55

$\operatorname{lgD} 0.3 \mu \mathrm{g} / \mathrm{mL}$

3.37
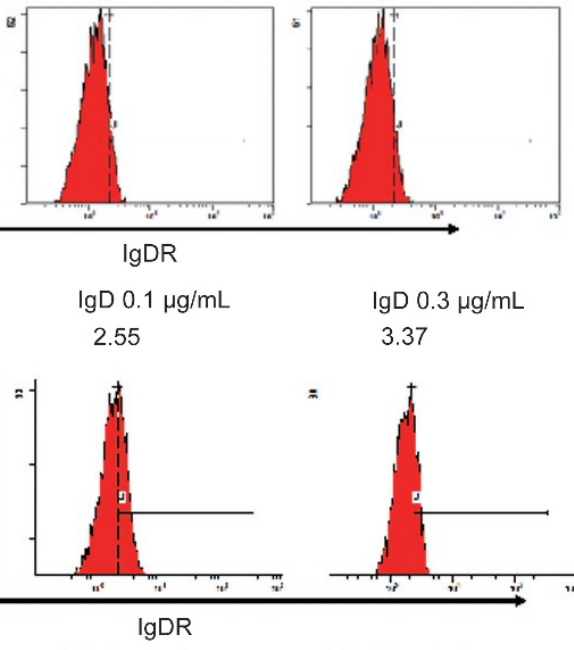

$\operatorname{lgD} 3 \mu \mathrm{g} / \mathrm{mL}$

4.69
B

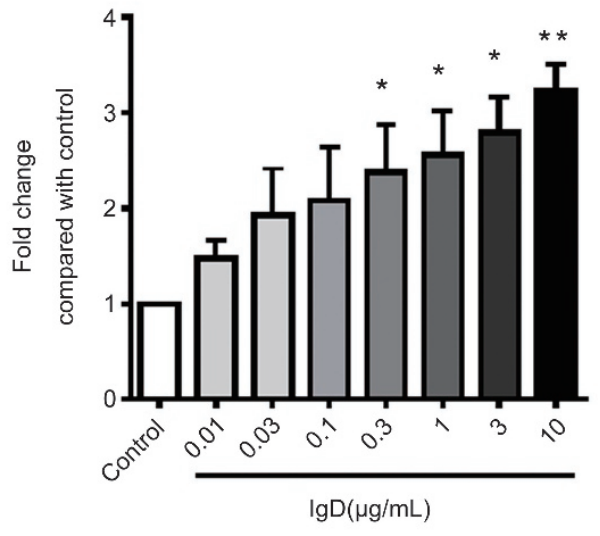

C

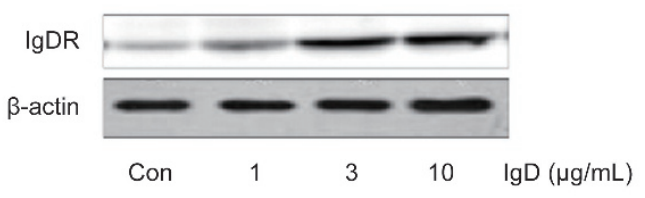

D

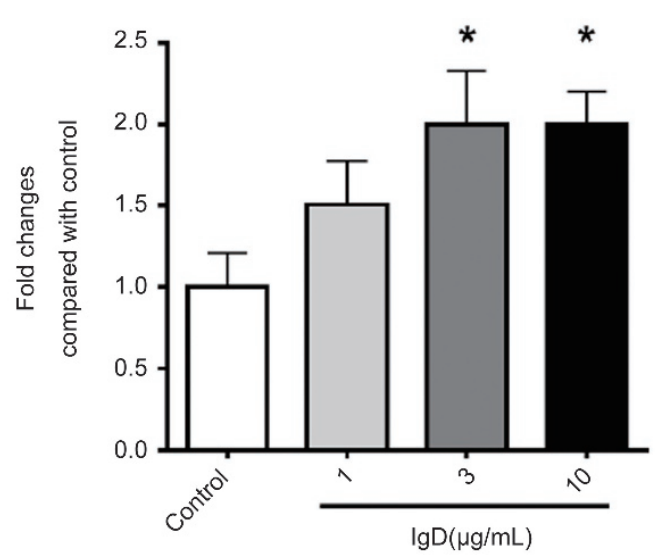

Figure 3. Effect of IgD on the expression of IgDR on RA-FLSs. RA-FLSs were stimulated with $0.1,0.3,1,3,10 \mu \mathrm{g} / \mathrm{mL}$ of IgD for $48 \mathrm{~h}$. (A) Dose dependent induction of IgDR expression on FLSs was assayed by flow cytometry. MFI: Mean fluorescence intensity. (B) Bar graphs show quantitative evaluation of expression of IgDR by MFI. (C) Expression of IgDR in FLSs was assayed by Western blotting. (D) Bar graphs show quantitative evaluation of expression of IgDR by densitometry. Data represent the mean \pm standard error of the mean $(n=3) .{ }^{*} P<0.05,{ }^{* *} P<0.01$ vs control.

human IgG1 $\left(K_{\mathrm{D}}=528 \mathrm{nmol} / \mathrm{L}\right)^{[26]}$.

In recent studies, we have found that the serum level of sIgD from RA patients was significantly higher $(91.93 \mu \mathrm{g} / \mathrm{mL})$ than that from healthy controls $(19.8 \mu \mathrm{g} / \mathrm{mL})$. Moreover, these findings indicate that increased $\operatorname{sigD}$ may play an important role in the pathogenesis of RA. Among the vari- ous pathological mechanisms that affect the synovium of RA, FLSs have been reported to play an important role in both the propagation of inflammation and joint damage ${ }^{[27,28]}$. FLSs induce the activation and accumulation of inflammatory cells and secreted growth factors, thus promoting angiogenesis ${ }^{[29]}$. In addition, RA-FLSs proliferate and migrate from the affected 

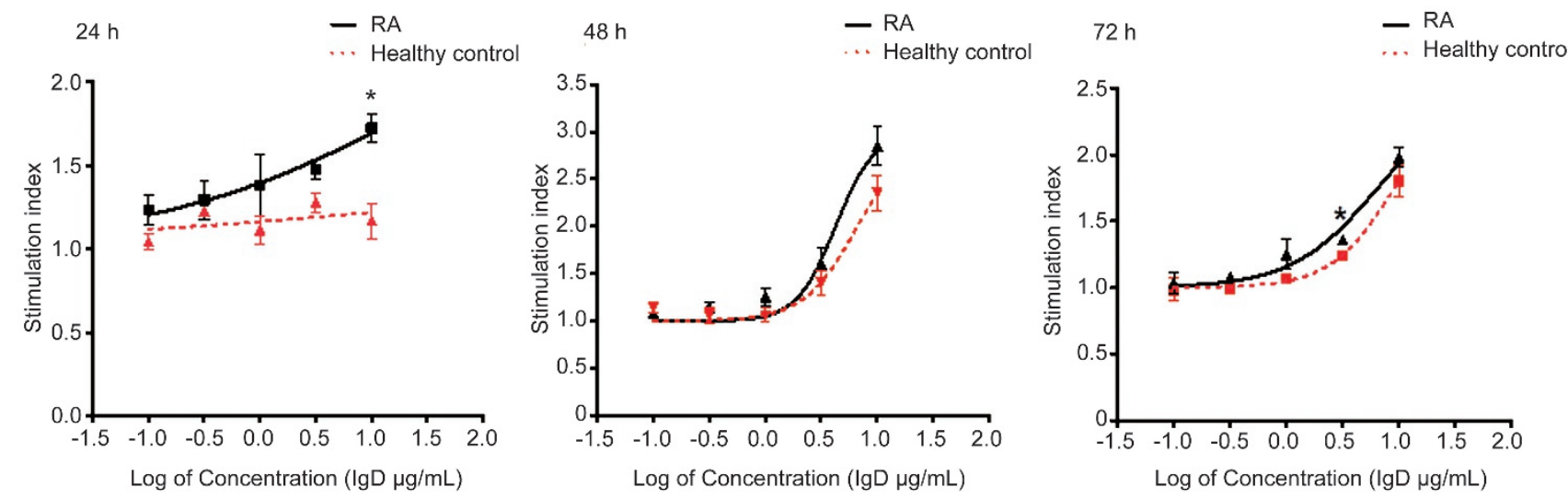

Figure 4. The stimulating effect of IgD on RA-FLSs and HC-FLSs. RA-FLSs and HC-FLSs were cultured with $0.1,0.3,1,3,10 \mu \mathrm{g} / \mathrm{mL}$ of IgD for $24 \mathrm{~h}$ (A), $48 \mathrm{~h}(\mathrm{~B})$, or $72 \mathrm{~h}(\mathrm{C})$. Data are expressed as the mean \pm SEM $(n=4)$, SI=absorbance at $450 \mathrm{~nm}$ in the cell cultures with drug divided by the absorbance in the culture with medium alone. ${ }^{*} P<0.05,{ }^{* *} P<0.01$ vs healthy control.

synovium to healthy synovium ${ }^{[30]}$. Our flow cytometry and Western blot results showed that $\mathrm{IgD}$ significantly increased the expression of IgDR in RA-FLSs. Further studies are necessary to investigate whether increased $\operatorname{IgD}$ may influence the function of FLSs and whether IgD might promote the pathological process in RA via upregulation of IgDR expression.

We have previously shown that $\operatorname{IgD}$ stimulation improves viability and promotes IgDR expression in Daudi cells and human PBMCs ${ }^{[10,11]}$. Indeed, we found that IgD enhanced the viability of human FLSs in a concentration-dependent manner. Moreover, the stimulation of viability of RA-FLSs by IgD was stronger than that of HC-FLSs at the same time point. In addition, the response of RA-FLSs to IgD was accelerated compared with that in HC-FLSs. These results indicated a close relationship between the response to $\operatorname{IgD}$ and expression of IgDR, thus suggesting that IgD-IgDR participates in joint destruction in RA.

Upon synoviocyte activation, several pro-inflammatory cytokines are essential for the development of $R A^{[31]}$. FLSs are key cells of the invasive synovium that may induce inflammation by activating cytokine and chemokine production ${ }^{[14]}$. Cytokines, such as IL-1 $\beta$, IL-6 and TNF- $\alpha$, stimulate RA-FLS invasion and increase the production of matrix metalloproteinases (MMPs), thus aggravating synovial inflammation and resulting in joint destruction ${ }^{[32]}$. By secreting CCL2 (MCP-1), activated resident synoviocytes recruit monocytes into the joints, thereby initiating inflammatory responses ${ }^{[33]}$. The immunoglobulin $\mathrm{IgD}$ has been shown to enhance the release of various pro-inflammatory cytokines from human PBMCs, including IL-6, IL-1 and TNF- $a$, in vitro ${ }^{[4,11,34]}$. Additionally, it enhances IL- 6 release by KU812 cells ${ }^{[2]}$. To our knowledge, the action of IgD on cytokine and chemokine release by RA-FLSs has not been investigated. In this study, IL-1 $\beta$, IL-6, TNF- $\alpha$ and MCP-1 were found to be released from activated FLSs in RA patients and appear to be the important participants in the pathophysiology of RA after treatment with IgD. How does IgD influence the function of FLSs? There are several possible explanations: first, IgD modulates the function of FLSs via interaction with IgDR. However, the signaling pathways downstream of IgDR on FLSs are still unknown. Second, IgD modulates the function of FLSs by upregulating the production of TNF- $\alpha$, IL-1 $\beta$, and IL- 6 . In turn, IL-1 $\beta$ promotes proliferation by MAPK and NF-KB activation ${ }^{[35-37]}$ while increasing the production of IL-1 $\beta$, IL- 6 , and RANKL. IL- 6 stimulates RANKL expression through IL-6/IL-6R/JAK pathway ${ }^{[38]}$. In RA patients, we have previously reported that IgD concentration is correlated with serum RANKL concentration ${ }^{[11]}$. The inflamed synovium is an optimal microenvironment for RANKL activation, which is essential for the differentiation of monocyte/macrophages into mature osteoclasts ${ }^{[39]}$. In patients with RA, FLSs have been shown to produce RANKL, which may promote osteoclast development ${ }^{[40]}$. Our present results showed that RANKL may be a key molecule downstream of the IgD-IgDR signaling pathway. IgD might enhance the level of RANKL in RA thereby leading to osteoclastogenesis at the site of pannus formation in the RA synovium. Further elucidation of IgDR and its signaling pathway is necessary to provide a clearer understanding of the molecular mechanisms by which FLS activation is regulated.

Our results suggested that excessive IgD in RA may enhance viability and cytokine/chemokine release by FLSs and improve FLS activation via cross-linking with IgDR. Therefore, the IgD-IgDR interaction may be a promising target for development of therapeutic agents for RA treatment.

\section{Abbreviations}

FLSs, fibroblast-like synoviocytes; IgA, immunoglobulin A; IgDR, IgD Fc receptor; $\mathrm{mIgD}$, membrane $\mathrm{IgD}$; $\mathrm{MCP}-1$, monocyte chemotactic protein; MFI, mean fluorescence intensity; MMPs, matrix metalloproteinases; PBMCs, peripheral blood mononuclear cells; PVDF, polyvinylidene fluoride; RA, rheumatoid arthritis; RANKL, nuclear factor-кB ligand; sIgD, secreted IgD; SLE, systemic lupus erythematosus.

\section{Acknowledgements}

This research was supported by the National Natural Science 
A

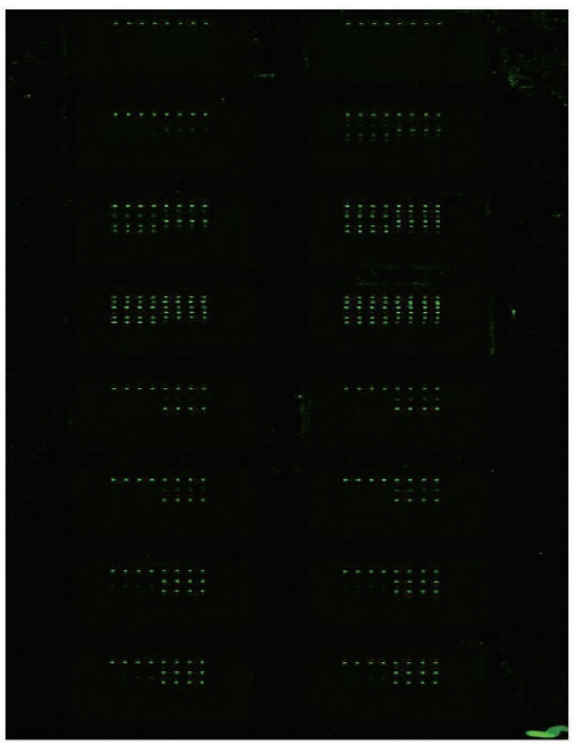

B

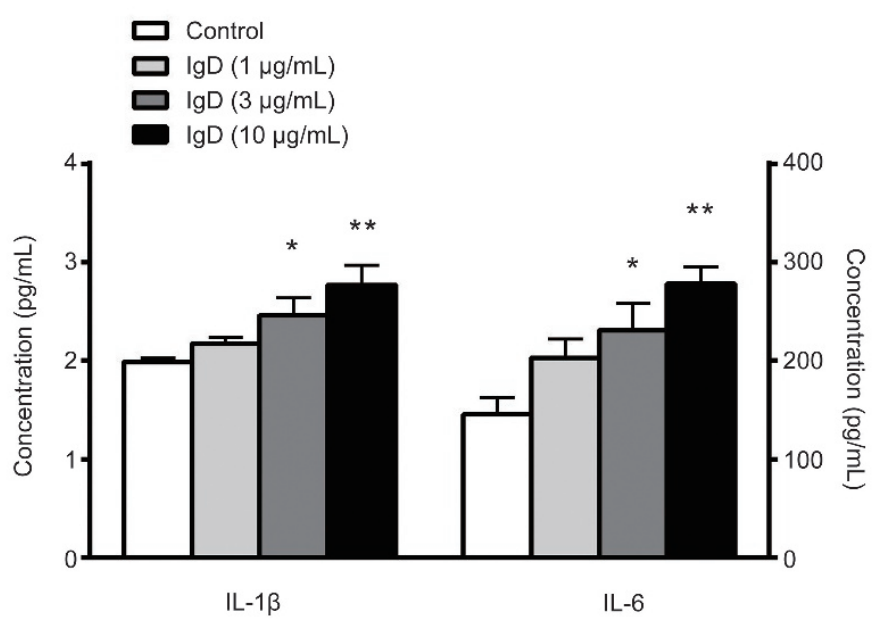

D
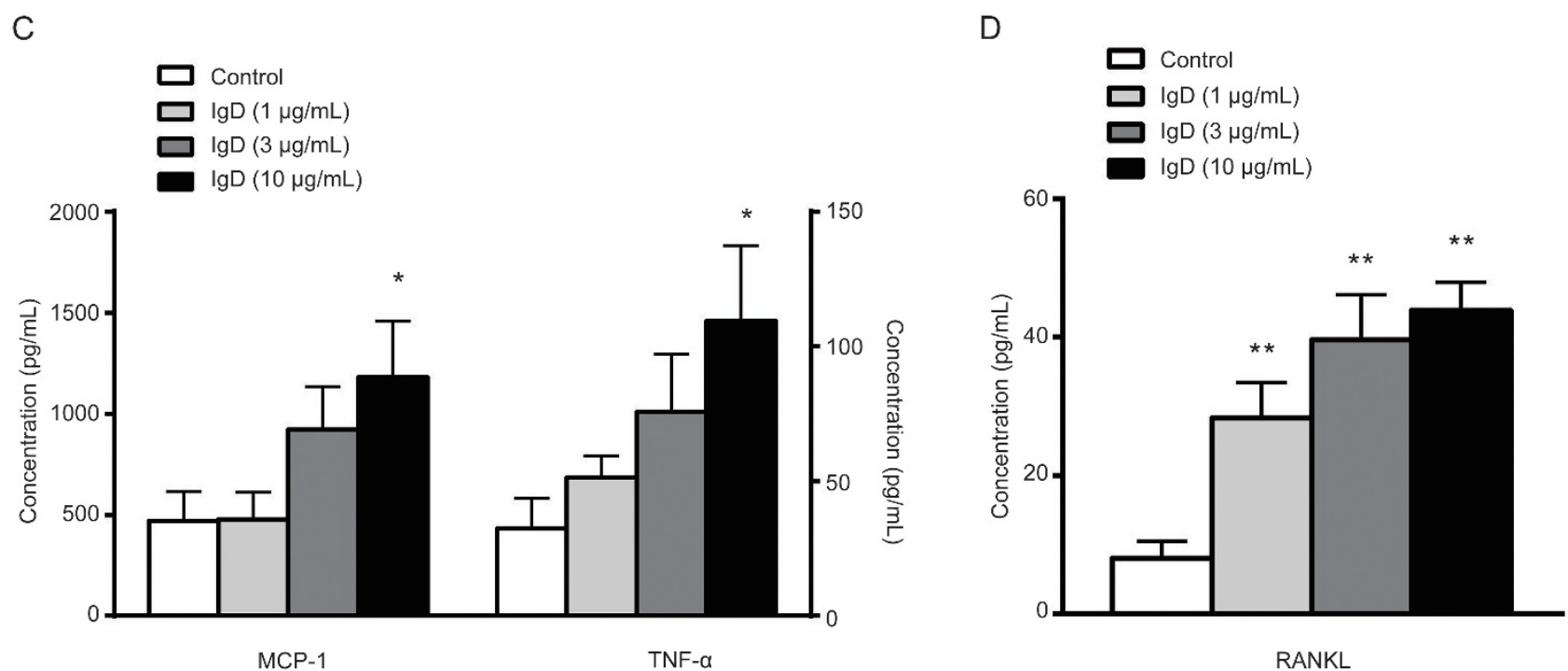

RANKL

Figure 5. Effects of IgD on inflammatory cytokine production in RA-FLS culture supernatant. RA-FLS culture supernatants were collected and treated with $\operatorname{IgD}(1,3$, or $10 \mu \mathrm{g} / \mathrm{mL})$ for $48 \mathrm{~h}$. The glass slide was scanned with a microarray scanner (A), levels of IL-1 3 and IL-6 (B), MCP-1 and TNF- $\alpha$ (C), RANKL (D) were measured. Data represent the mean \pm SEM $(n=4)$. " $P<0.05,{ }^{*}{ }^{*} P<0.01$ vs control.

Foundation of China (№ 81330081, 81473223, 81573443, and 81603121), Grants for Scientific Research of BSKY (No XJ201629) from Anhui Medical University and the Anhui Province Natural Science Foundation in the University (№ KJ2015A317).

\section{Author contribution}

Yu-jing WU designed and performed experiments and wrote the manuscript; Wen-sheng CHEN and Heng-shi CHEN participated in study design, performed the statistical analysis and revised the manuscript; Jin DONG and Xing DAI carried out the flow cytometry assays; Ying WANG collected all donors' clinical samples and prepared the FLSs; Yan CHANG and Xiao-yi JIA carried out the confocal microscopy analysis; Ling-ling ZHANG and Qiong HUANG performed the statis- tical analysis and helped to revise the manuscript; Wei WEI conceived the study and revised the manuscript. All authors read and approved the final manuscript.

\section{References}

1 Chen K, Cerutti A. New insights into the enigma of immunoglobulin D. Immunol Rev 2010; 237: 160-79.

2 Sechet B, Meseri-Delwail A, Arock M, Wijdenes J, Lecron JC, Sarrouilhe D. Immunoglobulin D enhances interleukin-6 release from the KU812 human prebasophil cell line. Gen Physiol Biophys 2003; 22: 255-63.

3 Rostenberg I, Penaloza R. Serum IgG and IgD and levels in some infectious and noninfectious diseases. Clin Chim Acta 1978; 85: 319-21.

4 Chen K, Xu W, Wilson M, He B, Miller NW, Bengtén E, et al. Immuno- 
globulin D enhances immune surveillance by activating antimicrobial, proinflammatory and B cell-stimulating programs in basophils. Nat Immunol 2009; 10: 889-98.

5 Wang P, Wei Z, Yan B, Huang T, Gou K, Dai Y, et al. Establishment of a transgenic mouse model with liver-specific expression of secretory immunoglobulin D. Sci China Life Sci 2012; 55: 219-27.

6 Hogarth PM. Fc Receptors: Introduction. Immunol Rev 2015; 268: $1-5$.

7 Coico RF, Xue B, Wallace D, Pernis B, Siskind GW, Thorbecke GJ. T cells with receptors for IgD. Nature 1985; 316: 744-6.

8 Nakamura T, Kubagawa H, Ohno T, Cooper MD. Characterization of an IgM Fc-binding receptor on human T cells. J Immunol 1993; 151: 6933-41.

9 Lakshmi TSM, Wu Y, Toporovsky I, Lima V, Coico RF. IgD receptormediated signal transduction in T cells. Cell Immunol 2001; 207 : 110-7.

10 Dai X, Wu Y, Jia X, Chang Y, Wu H, Wang C, et al. hlgD promotes human Burkitt lymphoma Daudi cell proliferation by accelerated $G_{1} / S$ transition via IgD receptor activity. Immunol Res 2016; 64: 978-87.

11 Wu Y, Chen W, Chen H, Zhang L, Chang Y, Yan S, et al. The elevated secreted immunoglobulin $\mathrm{D}$ enhanced the activation of peripheral blood mononuclear cells in rheumatoid arthritis. PLoS One 2016; 11 : e0147788.

12 Wu Y, Lakshmi TSM, Lima V, Coico R. Facilitated antigen presentation by $B$ cells expressing IgD when responding $T$ cells express IgDreceptors. Cell Immunol 1999; 192: 194-202.

13 Arnett FC, Edworthy SM, Bloch DA, McShane DJ, Fries JF, Cooper NS, et al. The American Rheumatism Association 1987 revised criteria for the classification of rheumatoid arthritis. Arthritis Rheum 1988; 31 : 315-24.

14 Miyabe Y, Miyabe C, Iwai Y, Yokoyama W, Sekine C, Sugimoto K, et al. Activation of fibroblast-like synoviocytes derived from rheumatoid arthritis via lysophosphatidic acid-lysophosphatidic acid receptor 1 cascade. Arthritis Res Ther 2014; 16: 461.

$15 \mathrm{Wu}$ CH, Li KJ, Siao SC, Chen YH, Wu TH, Tsai CY, et al. The binding affinity and molecular basis of the structure-binding relationship between urinary Tamm-Horsfall glycoprotein and tumor necrosis factor-alpha. Molecules 2012; 17: 11978-89.

16 McCall JR, Jacocks HM, Niven SC, Poli MA, Baden DG, Bourdelais AJ. Development and utilization of a fluorescence-based receptorbinding assay for the site 5 voltage-sensitive sodium channel ligands brevetoxin and ciguatoxin. J AOAC Int 2014; 97: 307-15.

17 Wang D, Hu S, Zhu J, Yuan J, Wu J, Zhou A, et al. Angiotensin II type 2 receptor correlates with therapeutic effects of losartan in rats with adjuvant-induced arthritis. J Cell Mol Med 2013; 17: 1577-87.

18 Chang SK, Gu Z, Brenner MB. Fibroblast-like synoviocytes in inflammatory arthritis pathology: the emerging role of cadherin- 11 . Immunol Rev 2010; 233: 256-66.

19 Rigante $\mathrm{D}$. The truth on IgD in the ploy of immune surveillance and inflammation. Immunol Res 2016; 64: 632-5.

20 Cerutti A, Chen K, Chorny A. Immunoglobulin responses at the mucosal interface. Annu Rev Immunol 2011; 29: 273-93.

21 Davis RS. Fc receptor-like molecules. Annu Rev Immunol 2007; 25: 525-60.

22 Leech MT, Morand EF. Fibroblasts and synovial immunity. Curr Opin Pharmacol 2013; 13: 565-9.

23 Chang SK, Mihalcik SA, Jelinek DF. B lymphocyte stimulator regulates adaptive immune responses by directly promoting dendritic cell maturation. J Immunol 2008; 180: 7394-403.

24 Phillips-Quagliata JM, Patel S, Han JK, Arakelov S, Rao TD, Shulman $\mathrm{MJ}$, et al. The IgA/IgM receptor expressed on a murine B cell lymphoma is poly-lg receptor. J Immunol 2000; 165: 2544-55.

25 Chakraborty A, Tannenbaum S, Rordorf C, Lowe PJ, Floch D, Gram $\mathrm{H}$, et al. Pharmacokinetic and pharmacodynamic properties of canakinumab, a human anti-interleukin-1ß monoclonal antibody. Clin Pharmacokinet 2012; 51: e1-18.

26 Gurbaxani B, Dostalek M, Gardner I. Are endosomal trafficking parameters better targets for improving $\mathrm{mAb}$ pharmacokinetics than FcRn binding affinity. Mol Immunol 2013; 56: 660-74.

27 Tough DF, Prinjha RK, Tak PP. Epigenetic mechanisms and drug discovery in rheumatology. Clin Med (Lond) 2015; 15: s64-71.

28 Miossec P. Rheumatoid arthritis: still a chronic disease. Lancet 2013; 381: 884-6.

29 Bartok B, Firestein GS. Fibroblast-like synoviocytes: key effector cells in rheumatoid arthritis. Immunol Rev 2010; 233: 233-55.

30 Townsend MJ, Monroe JG, Chan AC. B-cell targeted therapies in human autoimmune diseases: an updated perspective. Immunol Rev 2010; 237: 264-83.

31 Brennan FM, Mclnnes IB. Evidence that cytokines play a role in rheumatoid arthritis. J Clin Invest 2008; 118: 3537-45.

32 Samson M, Audia S, Janikashvili N, Ciudad M, Trad M, Fraszczak J, et al. Brief report: inhibition of interleukin-6 function corrects Th17/Treg cell imbalance in patients with rheumatoid arthritis. Arthritis Rheum 2012; 64: 2499-503.

33 Scanu A, Oliviero F, Gruaz L, Sfriso P, Pozzuoli A, Frezzato F, et al. High-density lipoproteins downregulate CCL2 production in human fibroblast-like synoviocytes stimulated by urate crystals. Arthritis Res Ther 2010; 12: R23.

34 Drenth JP, Göertz J, Daha MR, van der Meer JW. Immunoglobulin $D$ enhances the release of tumor necrosis factor-alpha, and interleukin-1 beta as well as interleukin-1 receptor antagonist from human mononuclear cells. Immunology 1996; 88: 355-62.

35 Aggarwal BB, Gupta SC, Kim JH. Historical perspectives on tumor necrosis factor and its superfamily: 25 years later, a golden journey. Blood 2012; 119: 651-65.

36 Zhou Q, Liu S, Yua D, Zhang N. Therapeutic effect of total saponins from Dioscorea nipponica Makino on gouty arthritis based on the NFKB signal pathway: An in vitro study. Pharmacogn Mag 2016; 12 : 235-40.

37 Wu HX, Chen JY, Wang QT, Sun WY, Liu LH, Zhang LL, et al. Expression and function of $\beta$-arrestin 2 stimulated by IL-1 $\beta$ in human fibroblastlike synoviocytes and the effect of paeoniflorin. Int Immunopharmacol 2012; 12: 701-6.

38 Choe JY, Park KY, Park SH, Lee SI, Kim SK. Regulatory effect of calcineurin inhibitor, tacrolimus, on IL-6/sIL-6R-mediated RANKL expression through JAK2-STAT3-SOCS3 signaling pathway in fibroblastlike synoviocytes. Arthritis Res Ther 2013; 15: R26.

39 Nagatani K, Itoh K, Nakajima K, Kuroki H, Katsuragawa Y, Mochizuki M, et al. Rheumatoid arthritis fibroblast-like synoviocytes express BCMA and are stimulated by APRIL. Arthritis Rheum 2007; 56: 3554-63.

40 Stanford SM, Svensson MN, Sacchetti C, Pilo CA, Wu DJ, Kiosses WB, et al. Receptor protein tyrosine phosphatase $\alpha$-mediated enhancement of rheumatoid synovial fibroblast signaling and promotion of arthritis in mice. Arthritis Rheumatol 2016; 68: 359-69. 